J. Lake Sci. (湖泊科学), 2013, 25(3): 422-427

http: //www. jlakes.org. E-mail: jlakes@niglas.ac.cn

(C) 2013 by Journal of Lake Sciences

\title{
复杂河道洪水预报系统研究——以淮河王家坝至小柳巷区间流域 为例"
}

常 露, 刘开磊, 姚 成, 李致家

(河海大学水文水资源学院,南京 210098)

摘 要: 随着社会经济的快速发展,洪水灾害造成的损失日益严重. 洪水预报作为一项重要的防洪非工程措施,对防洪、 抗洪工作起着至关重要的作用. 淮河洪水危害的严重性和洪水演进过程的复杂性使得淮河洪水预报系统的研究长期以 来受到高度重视. 本文以王家坝至小柳巷区间流域为例, 以河道洪水演算为主线,采用新安江三水源模型进行子流域降 雨径流预报,概化具有行蓄洪区的干流河道,进行支流与干流、行蓄洪区与干流的洪水汇流耦合计算,采用实时更新的基 于多元回归的方法确定水位流量关系,并以上游站点降雨径流预报模型提供的流量作为上边界条件、以下游站点的水位 流量关系作为下边界条件,结合行蓄洪调度模型, 建立具有行蓄洪区的河道洪水预报系统,再与基于 K-最近邻 ( KNN) 的 非参数实时校正模型耦合, 建立淮河中游河道洪水预报系统. 采用多年资料模拟取得了较好的预报效果, 并以 2003 和 2007 年大洪水为例进行检验,模拟结果精度较高,也证明了所建预报系统的合理性和适用性.

关键词: 洪水预报;行蓄洪;水位流量关系;实时校正

\section{Real-time flood forecasting system for complicated river channels: A case study from Wangjiaba to Xiaoliuxiang section in the Huaihe River basin}

\author{
CHANG Lu, LIU Kailei, YAO Cheng \& LI Zhijia \\ (College of Hydrology and Water Resources, Hohai University, Nanjing 210098, P. R. China)
}

Abstract: The losses caused by flood disasters are becoming increasingly serious with the rapid development of social economy. As an important non-engineering flood protection measure, real-time flood forecasting plays an important role in flood control. Due to the severity of flood disasters and the complexity of flood routing process in the Huaihe River basin, the research on flood forecasting system has been a focus for a long period. A case study from Wangjiaba to Xiaoliuxiang section is discussed and a research on flood forecasting system is presented in this paper. On the basis of the hydrologic characteristics in the study area, this paper takes flood flow routing as mainline, uses the Xin'anjiang model for runoff yield prediction, generalizes flood diversion and retarding regions, applies hydrologic and hydraulic methods to simulate flow routing in the main channels, and fits stage-discharge relationships by multiple regression method. A general system is established by integrating the above parts and then by coupling K-Nearest Neighbor method to attach real-time correction to forecasting results for the real-time forecasting system. Inspected in 2003 and 2007, the system achieved high prediction accuracy, which proves that the system is sound and can be applied to this basin.

Keywords: Flood forecasting; flood diversion and flood retarding; stage-discharge relationship; real-time correction

随着社会经济的快速发展,洪水灾害造成的损失日益严重. 洪水预报作为一项重要的防洪非工程措施, 对防洪抗洪工作起着至关重要的作用. 淮河流域水文预报研究历来是水文预报工作的重点难点. 进人汛期, 淮河干流中上游山区产生暴雨洪水并迅速汇集到中游, 由于中游河道比降突然平缓, 导致洪水下泄不畅, 沿 淮湖泊、洼地成为蓄滞洪水的场所. 中下游河网地区是一个锅底状平原洼地,一遇大暴雨极易形成洪涝灾 害. 在淮河中下游和淮北地区经常出现因洪致涝、洪涝并发的现象,危害最大的是大洪水与洪涝组合所造成

* 国家博士点基金项目 (20090094110005) 和国家自然科学基金项目 (41130639,51179045) 联合资助. 2012-07-18 收稿;2012-10-18 收修改稿. 常露,女,1988 年生, 硕士研究生;E-mail : changlu_88@ 163.com.

** 通信作者;E-mail:bbqx88@ 126.com. 
的灾害,在淮河下游地区还极易遭遇江淮并涨、淮沂并发、洪水风暴潮并袭的严重局面, 给流域造成很大的 经济损失, 因此淮河中上游流域的防洪安全具有极为重要的意义. 针对这一问题,急需分析流域降雨径流关 系,确定适合该流域的产汇流预报方法和干流河道洪水演算模型,建立适用的流域洪水预报系统, 为流域防 洪和水资源规划提供重要的依据.

1973 年赵人俊教授提出基于蓄满产流机制的新安江模型 ${ }^{[1]}$, 该模型普遍适用于湿润地区,精度较高, 在 国内得到了广泛的应用. 1990 年李致家等提出以模拟流量的马斯京根法、模拟河道水位的水文学方法、扩散 波非线性方法相结合的水位流量综合法,并在此基础上建立水文水力学耦合模型,模拟计算主河道洪水演 进过程, 与行蓄洪区调度模型耦合, 建立复杂河道的淮河洪水预报调度模型 ${ }^{[2]}$, 同时采用一维水力学方法的 河道演算模型进行比较研究. 1960s 以来实时校正技术被引人到洪水预报中,随着计算机技术的发展,该类 技术研究相当活跃,其中以误差自回归模型、卡尔曼滤波方法、基于人工神经网络的实时校正技术应用研究 较为广泛. 然而由于该类方法的参数较多, 参数值的设定极大地影响着实时校正的效果. 本文所应用的 K-最 近邻 (或 KNN, 下同) 实时校正方法从基于模式识别和相似预报的思想出发,建立非参数的 KNN 实时校正模 型,保证更长的预见期内的预报精度.

\section{1 流域简介与概化}

淮河流域地处我国东部, 介于长江和黄河两大流域之间 $\left(30^{\circ} 55^{\prime} \sim 36^{\circ} 36^{\prime} \mathrm{N}, 111^{\circ} 55^{\prime} \sim 121^{\circ} 25^{\prime} \mathrm{E}\right)$, 面积 约为 $27 \times 10^{4} \mathrm{~km}^{2}$. 淮河西起河南省桐柏山, 在江苏省境内三江营注人长江, 干流全长约 $1000 \mathrm{~km}$. 本文以淮 河王家坝至小柳巷区间流域为研究对象, 流域面积约为 $93320 \mathrm{~km}^{2}$, 主河道长 $540 \mathrm{~km}$, 其间主要支流有史河、 㴓河、颖河、浴河,沿该河段河道两侧建有多个行蓄洪区.

根据测站的分布状况, 支流以及行蓄洪区的分布位置, 以概化合理、模型建立方便为原则进行河道概 化, 将行蓄洪区概化为 16 个行洪区、4 个蓄洪区. 吴家渡一小柳巷区间行蓄洪区启用频率相对较低, 吴家渡与 小柳巷站之间的水位、流量相关关系较为单一,该区段单独进行河道洪水演算; 王家坝一鲁台子区间建有较 多行蓄洪区, 启闭频繁, 水文状况复杂, 该区段亦需建立相对复杂运算结构, 不宜与鲁台子以下区段的河道 演算模型合并.由此王家坝至小柳巷区间的洪水演算需要分为 3 个区段,河段概化如图 1.

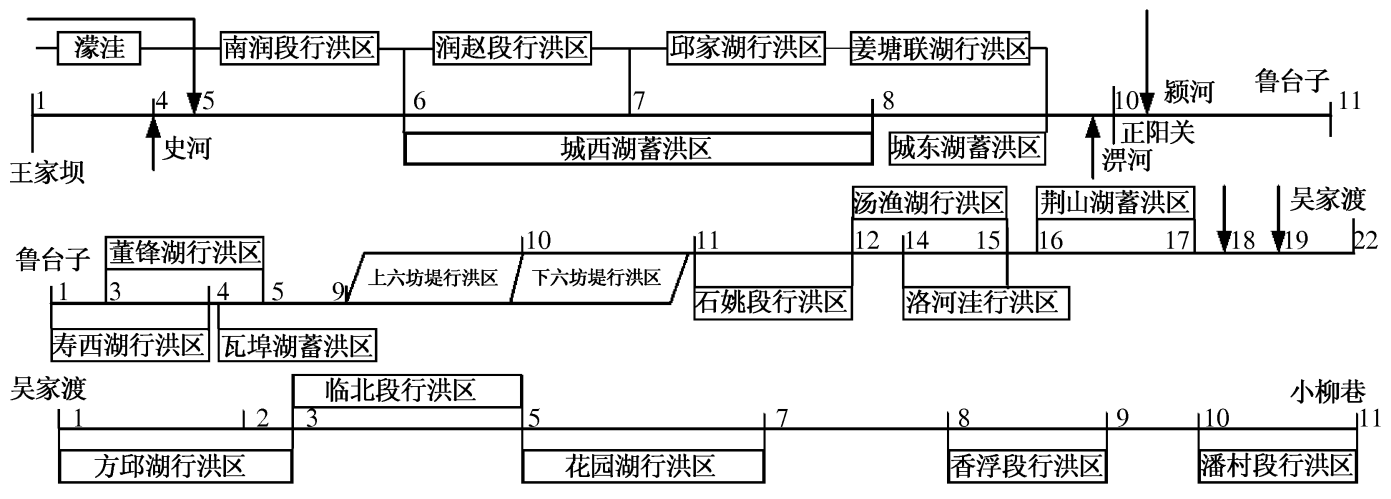

图 1 王家坝至小柳巷河段概化图

Fig. 1 Sketch of Wangjiaba-Xiaoliuxiang Channel

\section{2 流域降雨径流预报模型}

淮河王家坝至小柳巷区间流域,属于湿润流域, 由于三水源新安江模型普遍适用于湿润流域且模拟结 果精度较高 ${ }^{[3]}$, 因此, 采用三水源新安江模型进行流域降雨径流预报. 因鲁台子以下流域闸坝较多, 人工调 节径流情况普遍存在, 天然洪水的产汇流过程受到人为因素的影响较大, 实测洪水过程不能反映天然的产 汇流特性,故仅选取王家坝以上流域及王家坝至鲁台子区间流域为例进行说明. 王家坝以上流域划分为息 县、潢川、班台、北庙集流域; 王家坝至鲁台子区间流域划分为蒋家集、横排头、阜阳流域. 由于河道上存在节 
水闸, 率定参数时需要注意节水闸对汇流的影响 ${ }^{[4]}$. 考虑到流域汇流时间,本次研究时间步长取为 $6 \mathrm{~h}$.

2007 年 6 月 22 日至 7 月 28 日, 强降雨在淮河流域不断俳徊, 淮北地区最大 7 日降雨量达 $304 \mathrm{~mm}$, 大于 2003 年的 $282.5 \mathrm{~mm}$, 最大 1 日降雨量达 $108 \mathrm{~mm}$, 淮河流域遭遇了 1954 年以来的第二位流域性大洪水. 由于 雨区和降雨时段集中、雨量大, 导致淮河干流、支流水位普遍上涨, 河段水位全面超过警戒水位, 蒙洼、姜塘 湖蓄洪均启用. 新安江模型在此阶段对王家坝以上及王鲁区间流域的模拟结果见表 1.

各个子流域的洪量、洪峰误差,除阜阳和横排头外,均在 20\% 以内. 王家坝站洪峰误差只有 $0.77 \%$ （表 1 ), 为淮河中游的防汛决策提供重要的依据. 阜阳区间流域洪水预报, 由于流域内茨河铺闸人为控制放水流 量, 导致预报洪量偏小,洪峰提前; 横排头流域属于王家坝至鲁台子区间的支流，上游有佛子岭和响洪甸两 座大型水库, 闸坝较多, 流域天然的产汇流特性受人为影响而发生改变, 模型预报误差偏大. 总体而言, 流域 降雨径流预报结果合理,精度较高.

表 1 王家坝以上及王鲁区间流域洪水模拟特征值(2007 年 6 月 22 日至 7 月 28 日)

Tab. 1 Characteristic values of hydrological flood forecasting results in Wangjiaba basin and Wangjiaba-Lutaizi River basin (from Jun. 22th to Jul. 28th in 2007)

\begin{tabular}{|c|c|c|c|c|c|c|c|c|c|}
\hline 子流域 & $\begin{array}{c}\text { 总雨量/ } \\
\text { mm }\end{array}$ & $\begin{array}{l}\text { 实测水量/ } \\
\left(\times 10^{4} \mathrm{~m}^{3}\right)\end{array}$ & $\begin{array}{l}\text { 预报水量/ } \\
\left(\times 10^{4} \mathrm{~m}^{3}\right)\end{array}$ & $\begin{array}{c}\text { 洪量 } \\
\text { 误差/\% }\end{array}$ & $\begin{array}{c}\text { 实测洪峰/ } \\
\left(\mathrm{m}^{3} / \mathrm{s}\right)\end{array}$ & $\begin{array}{c}\text { 预报洪峰/ } \\
\left(\mathrm{m}^{3} / \mathrm{s}\right)\end{array}$ & $\begin{array}{c}\text { 洪峰 } \\
\text { 误差/\% }\end{array}$ & $\begin{array}{c}\text { 峰现时间 } \\
\text { 误差 }\end{array}$ & $\begin{array}{c}\text { 确定性 } \\
\text { 系数 }\end{array}$ \\
\hline 班台 & 522.7 & 332539.2 & 302822.0 & 8.93 & 2340 & 2400.0 & -2.56 & 7 & 0.86 \\
\hline 阜阳 & 379.4 & 283053.2 & 208742.9 & 26.25 & 2130 & 1838.5 & 13.69 & 6 & 0.65 \\
\hline 潢川 & 456.4 & 50084.6 & 51855.1 & -3.54 & 1480 & 1655.3 & -11.84 & 0 & 0.86 \\
\hline 横排头 & 322.9 & 16440.0 & 26037.7 & -58.39 & 492 & 686.2 & -39.47 & 0 & 0.62 \\
\hline 蒋家集 & 550.7 & 97859.6 & 114856.7 & -17.37 & 3150 & 2869.1 & 8.92 & 1 & 0.92 \\
\hline 息县 & 537.9 & 314134.5 & 369934.0 & -17.77 & 4330 & 4493.1 & -3.77 & 1 & 0.84 \\
\hline 北庙集 & 476.9 & 65136.6 & 63276.1 & 2.85 & 1490 & 1411.0 & 5.30 & 0 & 0.84 \\
\hline 王家坝 & 594.2 & 1212820.0 & 1143269.0 & 5.73 & 7240 & 7184.0 & 0.77 & 2 & 0.93 \\
\hline
\end{tabular}

\section{3 考虑行蓄洪的河道洪水演进模型}

具有行蓄洪区的河道洪水演进方法研究一直是淮河中游防汛工作的重点难点, 重点在于如何在考虑行 蓄洪区分洪影响的基础上合理概化河道和行蓄洪区,模拟河道和行蓄洪区的洪水演进 ${ }^{[5-6]}$; 难点在于如何确 定行蓄洪区的分洪流量. 以上游站点的降雨径流预报模型提供的流量作为上边界条件, 以下游站点的水位 流量关系作为下边界条件,采用一维河道水动力学模型, 建立具有行蓄洪区的淮河流域洪水预报模型.

行蓄洪区的概化是建立行蓄洪区与干流之间洪水演进模型、建立考虑具有行蓄洪区的河道洪水演进模 型的基础. 淮河王家坝一小柳巷段常用到的蓄洪区有城西湖蓄洪区、城东湖蓄洪区、瓦埠湖蓄洪区、荆山湖蓄 洪区等; 常用到的行洪区有南润段、润赵段、姜塘联湖、邱家湖、洛河洼、花园湖等. 出于对模型模拟稳定性的 考虑, 对行蓄洪区概化模型的建立不宜太过复杂, 但是对于防洪调度所需的行蓄洪区口门附近水位流量、淹 没区的范围等又需要保证有较高的精度. 综合考虑以上因素, 确定王家坝至小柳巷段行蓄洪区概化结果如 图 1 所示.

\section{1 蓄洪区的节点概化模型}

对于单一口门的蓄洪区, 如城东湖蓄洪区、瓦埠湖蓄洪区, 根据蓄洪区的具体运用情况可以将其概化为 水库型蓄洪区:在不考虑内部的洪水演进前提下, 认为内部水位一致, 并与蓄洪区的蓄量、库容呈正相关关 系, 如此建立蓄洪区节点概化模型能够较好地反映蓄洪区的运用机制, 依据蓄洪区口门的特征参数建立不 同流态下的口门过流公式, 可以较好地模拟干流与蓄洪区之间流量交换过程.

对于具备上下口门的蓄洪区, 如荆山湖蓄洪区, 出于防洪的需要, 要求该蓄洪区能够根据洪水规模、调 度需要实现蓄洪区一干流、干流-蓄洪区两种方式的调度过程, 并且荆山湖蓄洪区淹没区情况复杂, 进出洪口 门水位往往差别较大, 需要考虑蓄洪区内部的洪水演进过程, 得出上下口门的水位值, 进而实现与干流的洪 水演进模型耦合. 


\section{2 行洪区的节点概化模型}

淮河王家坝一小柳巷段常用的行洪区较多,常用的有扒堤行洪、炸堤行洪等方式,行洪流量难以实测得 到, 由参考文献 [5]可知,当行洪区口门的形状、河道冲淤状况变化不大时,可以用分流比去估算一次洪水过 程中行洪区的分洪流量,这也将在随后的水文预报中得到验证. 一般是洪水过后或者行洪区使用一段时间 后, 根据行洪口门的大小由水力学公式估算出来的特征值, 如最大流量等, 设行洪流量 $Q F_{i}$ 与干流分流后的 流量 $Q_{i}$ 之比作为分流比 $\left(\alpha_{i}\right)$. 一般估算出来的是最大行洪流量与干流总量之比:

$$
\alpha_{i}=Q F_{i} / Q_{i}
$$

所得分流比 $\alpha_{i}$ 可以用作下一场洪水或者当前时段之后的行洪区流量估算,或者用于流量反演验证.

行洪区与蓄洪区不同,一般通过进洪口门、退洪口门与干流衔接, 洪水由进洪口门人行洪区后, 当达到 行洪区库容量时会溢出行洪区, 从退洪口门返回干流河道或是淹没附近区域. 受行洪区的调蓄作用以及洪 水由干流至行洪区时过流断面突然变宽的影响, 行洪区内部洪水流速变缓, 在其内部蓄滞, 总的效果使得下 游的干流各站洪峰降低、峰现时间延后. 行洪区内部的洪水演进,采用不等分河段马斯京根法进行演算, 在 划分河段的时候已经考虑了口门的位置, 因此进退洪口门对应的河段编号与主河道对应,行洪区内部河段 划分与主河道一致.

\section{3 支流以及行蓄洪区与干流流量的塊合计算}

该研究河段有史河、㴓河、颖河、浴河等较大的支流,有濛洼、瓦埠湖、邱家湖等行蓄洪区. 进行干流河道 洪水演算时, 需要解决支流来水汇人干流以及行蓄洪区口门与干流交换流量这两个问题. 对于支流和蓄洪 区来水的计算,采用先合后演的水文学方法. 对于行洪区口门与干流交换流量的计算,行洪区上口门采用分 流比计算人流量, 行洪区内部用马斯京根法进行洪水演算, 当行洪区蓄满时水流从行洪区下口门流人干流, 此时该河段的支流、行蓄洪区都做集中人流处理, 在口门附近虚设断面, 设定该断面与上断面之间的 $\Delta X_{j}=$ 0 ,建立下列相关连接方程:

$$
Z_{i}=Z_{i+1}, Q_{i}+Q_{\mathrm{f}}=Q_{i+1}
$$

式中, $Q_{\mathrm{f}}$ 表示支流人流量, 当从河道中分洪或引水时 $Q_{\mathrm{f}}$ 取负值.

\section{4 基于多元回归方法确定的水位流量关系}

在平原河道,水文站点的水位流量关系除了受河道冲淤、河道阻塞等几何因素影响外,还受到洪水涨 落、回水顶托、行蓄洪区调蓄等水力因素影响, 水位与流量之间关系十分复杂. 淮河中游河道比降平缓, 河道 附加比降的作用不可忽略, 而且上游站出流往往受到其下游支流汇人和区间来水的回水顶托影响. 如史河 来水量稍大,其回水顶托影响可达王家坝站以上; 㴓河、颖河来水量稍大,其回水顶托影响可达润河集 (陈 郢) 站以上. 一旦出现回水顶托, 河道水面比降将进一步变缓, 同流量下的水位将明显抬高. 灌溉、排涝泵站, 灌溉、排涝泵站的运用对低水期水位流量关系也产生较大影响.

淮河中游流域洪水波的坦化现象明显, 下游站点洪水波相应波形发生延后, 当前站点的洪水水位与上 游前几个时刻洪水水位的相关关系较好, 对于受下游水位顶托的影响较明显的断面, 还需引人当前时刻的 下游水位, 最后引人当前站点当前的流量值 (由河道洪水演算直接得出), 建立与当前站点洪水水位的相关 关系 ${ }^{[7]}$. 通过逐步回归分析剔除与下游洪水水位关系不够紧密的因素, 以本次洪水已知资料进行模拟适线. 该方法综合考虑到落差指数法理论, 通过更新多元回归线性方程的系数达到实时调控站点水位流量关系的 目的 ${ }^{[8]}$.

图 2 中“多元回归模拟 0 ” 即以王家坝、润河集、临淮岗闸上、正阳关上一时刻水位为自变量, 建立鲁台子 水位流量关系, 模拟精度达到 $96.2 \%$; “多元回归模拟 1 ” 又引人鲁台子当前时刻来水, 建立与当前时刻鲁台 子水位的多元线性回归方程, 所得水位流量关系拟合精度达到 $97.1 \%$,精度有所提高, 特别对于高水部分拟 合精度提高明显,满足预报调度需要; “多元回归模拟 2 ”更从洪水过程连续性出发,引人鲁台子上一时刻水 位, 拟合的鲁台子水位流量关系精度达 $99.9 \%$,与实测点子几乎重合, 经多年资料验证流量一水位转换精度 较高, 可以用作洪水演进模型的稳定下边界条件. 


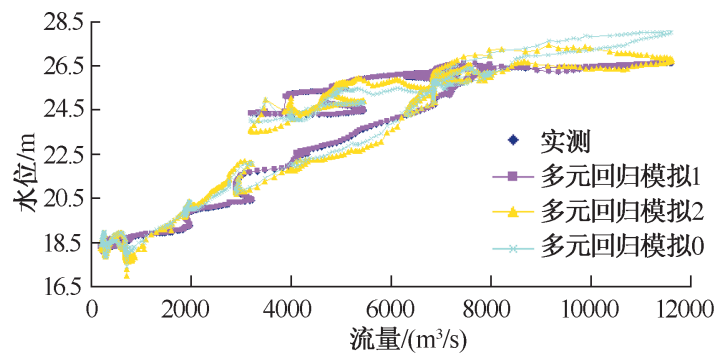
(2003 年 6 月 15 日至 7 月 22 日)

Fig. 2 Results of stage-discharge relationship at Lutaizi Station (from Jun. 15th to Jul. 22th in 2003)

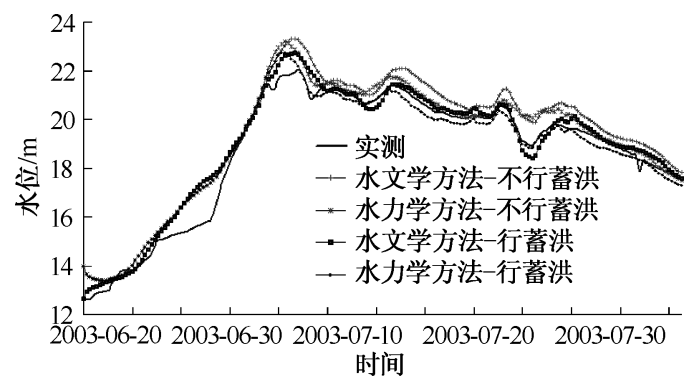

图 3 吴家渡站考虑行蓄洪的洪水水位过程模拟 结果对比(2003 年 6 月 20 日至 8 月 5 日)

Fig. 3 Flood routing results with considering flood diversion and flood retarding at Wujiadu Station

(from Jun. 20th to Aug. 5th in 2003)

表 2 吴家渡站水文学与水力学方法洪水 洪峰流量预报结果对比 (2003 年 6 月 20 日至 8 月 5 日)

Tab. 2 Comparison of flow peak forecasting results with hydrologic and hydraulic method at Wujiadu Station

\begin{tabular}{clllll}
\hline \multirow{2}{*}{ 指标 } & \multicolumn{2}{c}{ 水文学方法 } & & \multicolumn{2}{c}{ 水力学方法 } \\
\cline { 2 - 3 } \cline { 5 - 6 } & 不行蓄洪 & 行蓄洪 & & 不行蓄洪 & 行蓄洪 \\
\hline 确定系数 & 0.919 & 0.962 & & 0.947 & 0.964 \\
洪峰相对误差 & $5.9 \%$ & $3.2 \%$ & & $5.4 \%$ & $3.2 \%$ \\
洪峰绝对误差 $/ \mathrm{m}$ & 1.29 & 0.70 & & 1.18 & 0.70 \\
\hline
\end{tabular}

图 2 鲁台子站水位流量关系拟合结果 (from Jun. 20th to Aug. 5th in 2003)

\section{5 不同方法模拟洪水演进的结果对比}

用 2003 和 2007 年大洪水实测水位流量资料 以及行蓄洪区调度资料, 对所建立的考虑行蓄洪 调度的洪水预报调度模型进行检验, 模拟结果合 理、精度较好. 鲁台子至吴家渡区间行蓄洪区颇多， 应用频繁, 吴家渡站的洪水过程较能体现行蓄洪调 度对洪水过程的影响, 吴家渡站 2003 年 6 月 20 日 至 8 月 5 日洪水水位过程模拟结果对比见图 3.

考虑行蓄洪调度影响的洪水演算精度比不考 虑行蓄洪的高, 尤其是洪峰以及峰现时间的预报 精度有了较大程度的提升. 图中显示的 2003 年 7 月 4 日之前水文学、水力学方法所模拟的行蓄洪 与不行蓄洪方案基本重合, 这是因为在 2003 年 7 月 4 日吴家渡站洪峰到来之前, 各关键站点水位 尚在警戒线以下,未启用行蓄洪区, 分洪流量为 零. 预报结果汇总见表 2 .

水文学、水力学方法在吴家渡站的预报结果 较好, 水力学模型的预报结果要优于水文学方法 的预报结果, 在考虑行蓄洪之后水文、水力学预报 方法的结果均有较大提高, 行蓄洪之后的水文学 方法以及水力学方法预报的确定性系数均达到甲 级精度, 大于 0.90 . 各项指标如表 2(其中确定性 系数为能体现差异, 取 3 位有效数字) 洪峰误差为 直接模拟预报得出, 若用于实时发布还需要经过 实时校正的过程,精度会更高.

\section{4 基于 KNN 的实时校正方法研究}

\section{1 基于 $\mathrm{KNN}$ 的实时校正方法原理}

采用确定性模型预报出来的洪水流量 (水 位) 过程线因其不确定性的存在, 而需要在预报出 结果之后, 根据历史洪水资料或者预报员的经验, 对结果进行修正,这种修正中存在着模式分类、相 似相关的思想, 即相似的条件下发生的“动作” 会 产生相似的结果 ${ }^{[9]}$, 这种修正是合理的,并被实践 检验有效. 笔者尝试引用基于 KNN 的样本分类方 法从已知的历史资料,或是有实测资料对照的预 报结果中推求当前流量、水位预报误差的可能值, 从而实现对预报结果的实时修正.

KNN 方法是应用广泛的模式识别分类方法, 可用于线性可分或不可分的多类样本识别, 基于由历史误差序列建立的大量样本, 可以在其中找到与目标 样本最近邻的 $K$ 个点, 并根据这 $K$ 个样本的特征, 估计未知样本的值 ${ }^{[10-11]}$. 基于 $\mathrm{KNN}$ 的实时校正方法的实 现步骤如下:

(1) 按照时间先后顺序建立有限长的预报误差系列 $\left(p_{1}, p_{2}, \cdots, p_{m}\right), m$ 为实测期样本数量;

(2) 从误差自回归的角度,笔者认为当前时段的预报误差 $p_{t+e x t}=f\left(p_{t-\theta}, \cdots, p_{t-2}, p_{t-1}\right)$, 则样本的点子坐 标为 $\left(\left(p_{i-\theta}, \cdots, p_{i-2}, p_{i-1}\right), p_{i+e x t}\right), i=1 、 2 、 3 \cdots m-1, e x t$ 为实时校正预见期. 记 $X_{i}=\left(p_{i-\theta}, \cdots, p_{i-2}, p_{i-1}\right)$ 对应 
的样本点子集合为 $\left\{\left(X_{i}, p_{i+e x t}\right)\right\}$;

(3) 从 $\mathrm{KNN}$ 理论出发从 $\left\{X_{i}\right\}$ 中寻找关于 $X_{t}$ 最近的 $K$ 个样本, 对应点子的纵坐标以 $\left\{X_{j}\right\}$ 与 $X_{t}$ 之间反距 离权重加权得到预报误差校正值 $p_{t+e x t}=\sum_{j=1}^{k}\left(\lambda_{j} p_{j}\right) / \sum_{j=1}^{k} \lambda_{j}$, 其中 $\lambda_{j}=1 / L_{j}^{\prime}, L_{j}^{\prime}$ 为 $X_{j}$ 与 $X_{t}$ 的距离, $j=1 、 2 、 3 \cdots K$.

\section{2 基于 $\mathrm{KNN}$ 的实时校正方法应用}

为对比实时校正的应用效果, 采用前述的 2007 年洪水,并增加行蓄洪调度较少的 20040809、20050729、 20080803 三场洪水进行模拟验证, 从洪峰相对误差、确定性系数两个方面考察校正能力, 从校正结果可知, 相对于未经校正的预报结果, 经 KNN 方法实时校正的预报结果能够较大程度、稳定地提高预报精度 (表 3 ). 另外, 从预见期的角度进行观察，常规反馈模拟实时校正方法的校正预见期为一个时段长, 而 KNN 实时校 正方法在足够多样本的支持下, 可以保持在较长的预见期内仍保持有较高的精度 $(\Delta T=6 \mathrm{~h})$.

表 3 不同预见期的 KNN 校正算法校正效果比较

Tab. 3 Results of different forecast periods by KNN real-time correction methods

\begin{tabular}{cccccccc}
\hline \multirow{2}{*}{ 洪号 } & 指标 & 未校正 & \multicolumn{5}{c}{ KNN 校正 } \\
\cline { 5 - 8 } & & & $\Delta T$ & $2 \Delta T$ & $3 \Delta T$ & $4 \Delta T$ & $5 \Delta T$ \\
\hline \multirow{2}{*}{20040809} & 确定性系数 & 0.72 & 0.86 & 0.79 & 0.77 & 0.77 & 0.76 \\
& 洪峰相对误差 & $-2.1 \%$ & $-2.1 \%$ & $-2.1 \%$ & $-2.1 \%$ & $-2.1 \%$ & $-2.1 \%$ \\
\multirow{2}{*}{20050729} & 确定性系数 & 0.88 & 0.96 & 0.95 & 0.95 & 0.94 & 0.94 \\
& 洪峰相对误差 & $8.9 \%$ & $5.9 \%$ & $6.4 \%$ & $6.8 \%$ & $6.5 \%$ & $6.6 \%$ \\
\multirow{2}{*}{200707030803} & 确定性系数 & 0.98 & 0.99 & 0.99 & 0.99 & 0.99 & 0.99 \\
& 洪峰相对误差 & $-0.6 \%$ & $0.3 \%$ & $-0.5 \%$ & $-0.4 \%$ & $-0.4 \%$ & $-0.6 \%$ \\
& 确定性系数 & 0.89 & 0.95 & 0.93 & 0.92 & 0.91 & 0.91 \\
& 洪峰相对误差 & $0.3 \%$ & $0.1 \%$ & $0.3 \%$ & $0.3 \%$ & $1.2 \%$ & $3.4 \%$ \\
\hline
\end{tabular}

\section{5 总结}

淮河洪水危害的严重性和洪水演进过程的复杂性使得淮河洪水预报调度模型的研究长期以来得到充 分重视. 淮河中上游王家坝一小柳巷区间为流域, 因为其复杂的流域产汇流机制以及洪水调度状况,一直是 水文模拟预报工作的重点与难点. 本文在对该流域的产汇流模拟、河道洪水演进模拟、边界条件设定、结果 优化修正模型等模块进行研究并耦合, 能够较好地模拟该流域的洪水演进状况, 对于以防洪工程较多且启 用频繁、支流较多, 且上下游水位流量相关关系不够单一的复杂流域洪水模拟预报研究,具有一定的参考价 值. 通过建立行蓄洪区与旁侧人流的概化模型, 实现与干流洪水演进模型的耦合, 能够较为方便有效地考虑 行蓄洪区等对干流洪水演进的影响, 然而概化模型无法针对行蓄洪区的淹没范围、受灾损失提供客观详实 的数据, 对于防洪要求较高的地区, 更需要单独建立相关的灾损计算模型. 另外, 拟将历史洪水过程与当前 预报洪水过程进行比较研究, 以期进一步提高 KNN 实时校正方法的校正能力.

\section{6 参考文献}

赵人俊.流域水文模拟一一新安江模型和陕北模型. 北京: 水利电力出版社, 1984:106-130.

[ 2 ] 李致家,李纪人. 河道流量和水位模拟综合法介绍. 人民黄河, 1990,4:16-20.

[ 3 ] Anderson MG, Burt TP. Hydrological forecasting. New York: John Wiley \& Sons, $1985: 23-39$.

[ 4 ] 辛朋否, 李致家,汤嘉辉等. 新安江模型参数全局优化. 湖泊科学, 2011,23 (4):626-634.

[ 5 ] 李致家. 具有行蓄洪区的河道流量演算方法探讨. 水科学进展, 1997,3:65-70.

[ 6 ] Parthasarathi C. Multiple inflows muskingum routing model. Journal of Hydrologic Engineering, 2007, (1) :473-481.

[ 7 ] 门玉丽,夏 军,叶爱中等. 水位流量关系曲线的理论求解研究. 水文,2009,29(1):1-3,62.

[ 8 ] 张德伟,李淑琴, 徐 实. 用虚拟水位流量关系作多元回归的相应水位法洪水预报. 东北水利水电, 1993,5:13-16.

[9] 孙占东. 水文时间序列数据挖掘研究与应用——以频繁序列研究为例 [ 学位论文]. 南京: 中国科学院南京地理与 湖泊研究所,2003.

[10］翟宇梅,赵瑞星. 概率天气预报的 K 近邻非参数估计仿真模型. 系统仿真学报,2005,17(4) : 786-788.

[11] Karlsson M, Yakowitz S. Nearest-neighbor methods for nonparametric rainfall-runoff forecasting. Water Resources Research, $1987,23(7): 1300-1308$. 